AMERICAN JOURNAL OF SOCIAL AND MANAGEMENT SCIENCES

ISSN Print: 2156-1540, ISSN Online: 2151-1559, doi:10.5251/ajsms.2010.1.1.1.12

(C) 2010, ScienceHuß, http://www.scihub.org/AJSMS

\title{
Effectiveness of planning and implementation stages of the ISO 14001 standards EMS at the Obuasi gold mine, Ghana Gordon Foli ${ }^{1^{*}}$, Jonathan N. Hogarh ${ }^{2}$ and Philip Antwi-Agyei ${ }^{2}$ \\ ${ }^{1}$ Department of Earth and Environmental Science University for Development Studies, Navrongo Campus; Navrongo, Ghana \\ ${ }^{2}$ Department of Environmental Science \\ Kwame Nkrumah University of Science and Technology, Kumasi, Ghana \\ ${ }^{*}$ Corresponding Author: gordon.foli01@gmail.com \\ P.O. Box 24, Navrongo Campus, Navrongo, Ghana \\ Tel: +23320 8134579; +23326 8134579; Fax: +233742 22321
}

\begin{abstract}
This paper evaluated the effectiveness of the planning and implementation stages of the ISO 14001 Standards Environmental Management System (EMS) at the Obuasi gold mine in Ghana. The purpose was to identify growth factors, challenges and opportunities for improving process efficiencies through ISO 14001 Standards EMS implementation. A modified ISO 14031 Standards criterion for performance evaluation at the Plan-Do stages was adopted. In all, planning and implementation at eighteen business units were evaluated over a two-year period. Nine out of ten systems procedures evaluated scored above certification audit pass mark of $90 \%$. Environmental Aspect and Impact Identification, and Competence training improved in performance over the study period by average values of $151 \%$ and $104 \%$, respectively, while significance rating and environmental observations respectively dropped by $12 \%$ and $64 \%$. Environmental training and awareness creation, good aspect and significance rating schemes, establishment of performance reward system for meeting environmental objectives, among others, could serve as key factors that can sustain the ISO 14001 standards EMS. Notable challenges of the EMS were: lack of guide tools, apathetic attitudes, group certification concept, cost constrains, legacy issues and complexity of company's operations.
\end{abstract}

Keywords: Environmental Planning, Environmental Management System, ISO 14001 Certification, Obuasi, Ghana

\section{INTRODUCTION}

For several years in Ghana, environmental degradation due to mining was viewed as a normal consequence associated with the industry. This was so, since there were virtually no environmental guidelines for managing the environmental issues at the time. Things however, began to change in the early 1990s due to growing consciousness by state legislators, the public and other concerned groups regarding environmental pollution. This led to the enactment of the Environmental Protection Agency, EPA (Ghana) Act 490 of 1994, and the Parliamentary Legislative Instrument LI1652 of 1999 (Allotey et al., 2006) to address matters concerning the environment. These legislations were in accordance with the outcome of the United Nations Conference on Environment and Development (UNCED) held in Rio de Jeneiro in 1992 (Matouq, 2000; Emilson and Hjelm, 2002; Massoud et al., 2010).

The coming into force of environmental legislations in Ghana might have compelled or perhaps motivated major mining companies such as the Obuasi gold mine (Fig. 1), to opt for the ISO 14001 Standards Environmental Management System (EMS). ISO14001 is a process standard designed to articulate the characteristics of the components of a management system; and also requires that, organisations formulate an environmental policy for planning, implementing, monitoring and measurement, for effectiveness (Petroni, 2001; Barla, 2007; Massoud et al., 2010). 


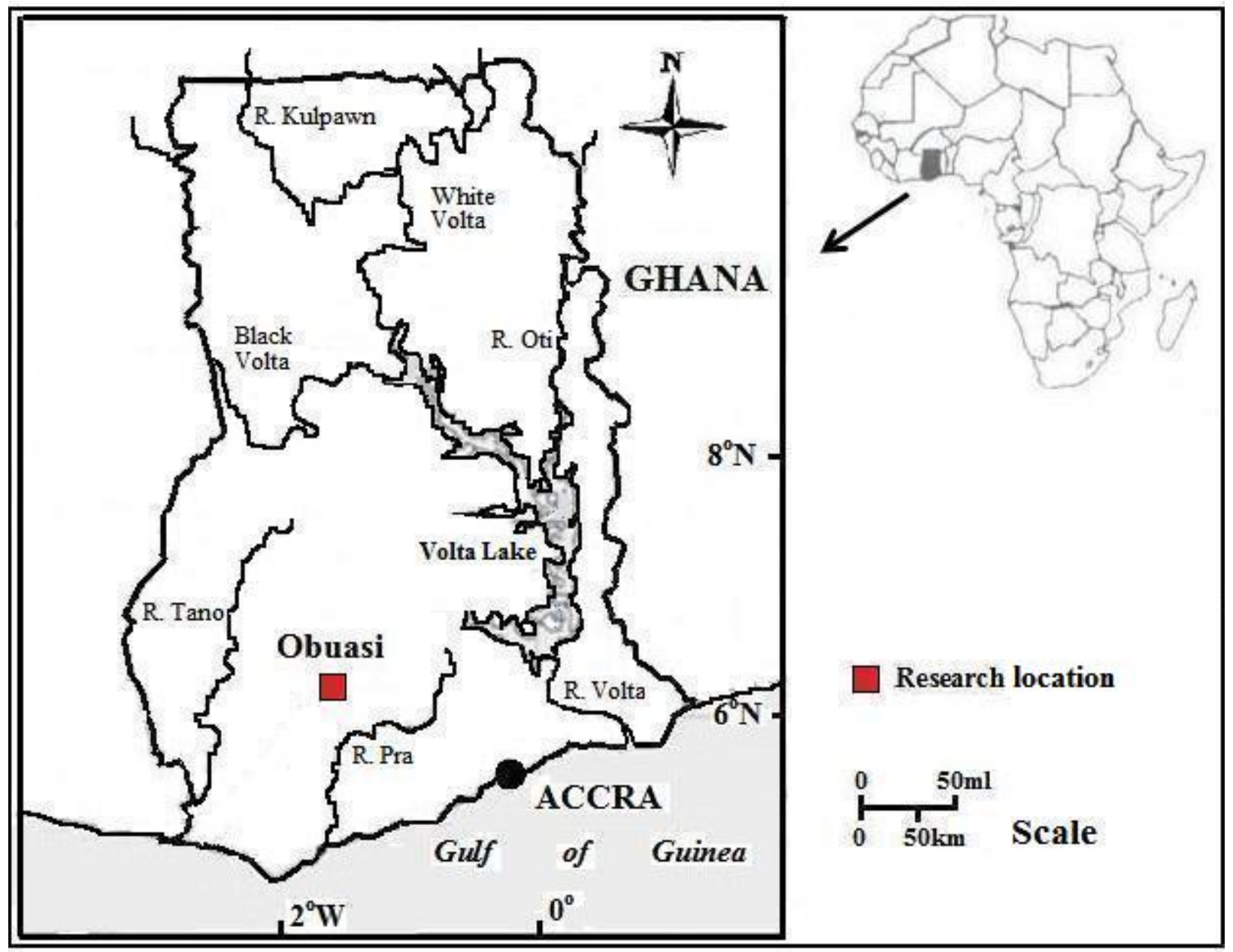

Fig. 1: Map of Ghana showing research location.

Having operated for over a century, the Obuasi mine had some legacy issues that were incorporated into the newly adopted ISO 14001 standards EMS certification process. The Obuasi mine ISO 14001 standards EMS certification project was initiated in March 2006 and attained in November 2006. ISO 14001 Standards EMS by itself is not enough to improve environmental performance, except that it is guided at all levels of the EMS by a performance evaluation methodology like ISO 14031 Standards. With such performance evaluation tools, an organization's environmental performance criteria set by management are evaluated based on environmental aspects and impacts performance to meet objectives of the EMS in a sustainable way (Coelho et al., 2000, Coelho and Moy, 2001, Stone and van Berkel, 2004). A good environmental management system is holistically based on the Plan-Do-Check-Act (PDCA) business process improvement model (Stone and van Berkel, 2004;
Seifert, 2005; Viegas, 2005); with Check-Act (CA) stages as key focus for justifying certification (Poder, 2006).

Primarily, a good CA stage of an EMS can only be achieved based on the perfectness of the Plan-Do (PD) stages, in order to be able to achieve the needed justification. Under the circumstances, environmental aspects, which play a crucial role in the formulation of effective environmental policy, thus laying the basis for the whole environmental management system (Poder, 2006), could be used as one of the key metrics for evaluation. This is justifiable because ISO 14031 standard as part of the ISO 14000 family makes no recommendations about choosing metrics for management (Morhardt et al., 2002; Stone and Berkel, 2004). However, Stone and Berkel, (2004) listed a set of critical factors as: (i) understanding of the issues, (ii) clearly defined direction and goals, (iii) achievable and compatible, 
(iv) top level commitment, and (v) efficient and effective communication.

Morhardt et al. (2002) noted that the business effects of undertaking environmental and social improvements is still not as clear, largely because of difficulties in testing causality. This underscores the importance of seeking clearly defined metrics for evaluating environmental aspects of corporate actions. Presently, the identification and evaluation of environmental aspects in ISO 14001 EMS implementation is regarded as one of the most difficult and problematic issues in the implementation initiatives (Mohammed, 2000; Babakri et al., 2003; Zobel and Burman, 2004). Significant rating through risk assessment is also equally conceived as a stage often plagued with ambiguities, inconsistencies and complexities that sometimes cause companies to attempt to cover-up real environmental issues and ending up performing below expectation (Poder, 2006). For instance, Sepalla (1994) described a rather simplistic risk assessment methodology, which based overall significance on only probability and severity (Poder, 2006); as against more precise trends in modern business circles (Asante-Duah, 1998; Fletcher, 2005). Fletcher (2005) indicated that, the more precise the methodology, the less the ambiguity in assigning ratings.

Complexities in establishing the datum for EMS are probably worsened by legacy issues. Legacy issues are generally not directly linked to any specific productive stage of current operation since they are inherited hence, might not attract direct attention from management. The emergence of ISO 14001 standards ensures that such legacy issues are incorporated into a company's EMS and managed together with current issues in spite of the financial challenges. Failure to plan and implement correctly a system that will incorporate and address the legacy issues this way might result in some situations escalating into uncontrollable issues, such as those that pertain to acid mine drainage (Singh, 1987; da Rosa and Lyon, 1997). Hassell (2005) indicated that EMS effectiveness based on specific identified factors has not been really evaluated and documented widely in industry; thereby leaving enough room for skepticism about whether or not ISO 14001 standards certification actually improves environmental performance (Fryxell et al., 2004). As a newly implemented standard, similar perceptions were anticipated at the Obuasi mine in Ghana. In this regard, it is necessary to examine whatever system that was certified to set the stage for managing without any doubts about the local EMS.

This study therefore evaluated the planning, implementation and operation stages of the systems elements of the ISO 14001 standards EMS at the Obuasi mine to assess the effectiveness of the system.

\section{METHODOLOGY}

Modification of model and metrics: The methodology for this study followed a modified PlanDo model (Fig. 2) derived from the ISO 14031 Standardized Plan-Do-Check-Act model (Stone and van Berkel, 2004; Viegas, 2005). Comparable to critical factors outlined by Stone and van Beckel (2004), the following components of the Plan-Do stages were chosen as key metrics for evaluation:

(i) Environmental aspects and impact;

(ii) Legal and other requirements;

(iii) Objectives, targets and programs;

(iv) Resources, roles, responsibility and authority;

(v) Competence, training and awareness;

(vi) Communication;

(vii) Documentation;

(viii) Control of documents;

(ix) Operational control; and

(x) Emergency preparedness and response.

Systems procedures based on these metrics were audited for documentation at eighteen (18) business units on the mine. These business units included Safety, health and environment; Human resources; Engineering; Metallurgy; Mining; Finance; and Mineral resource management. Eleven supply chains designated (C1...C11) were also covered. 


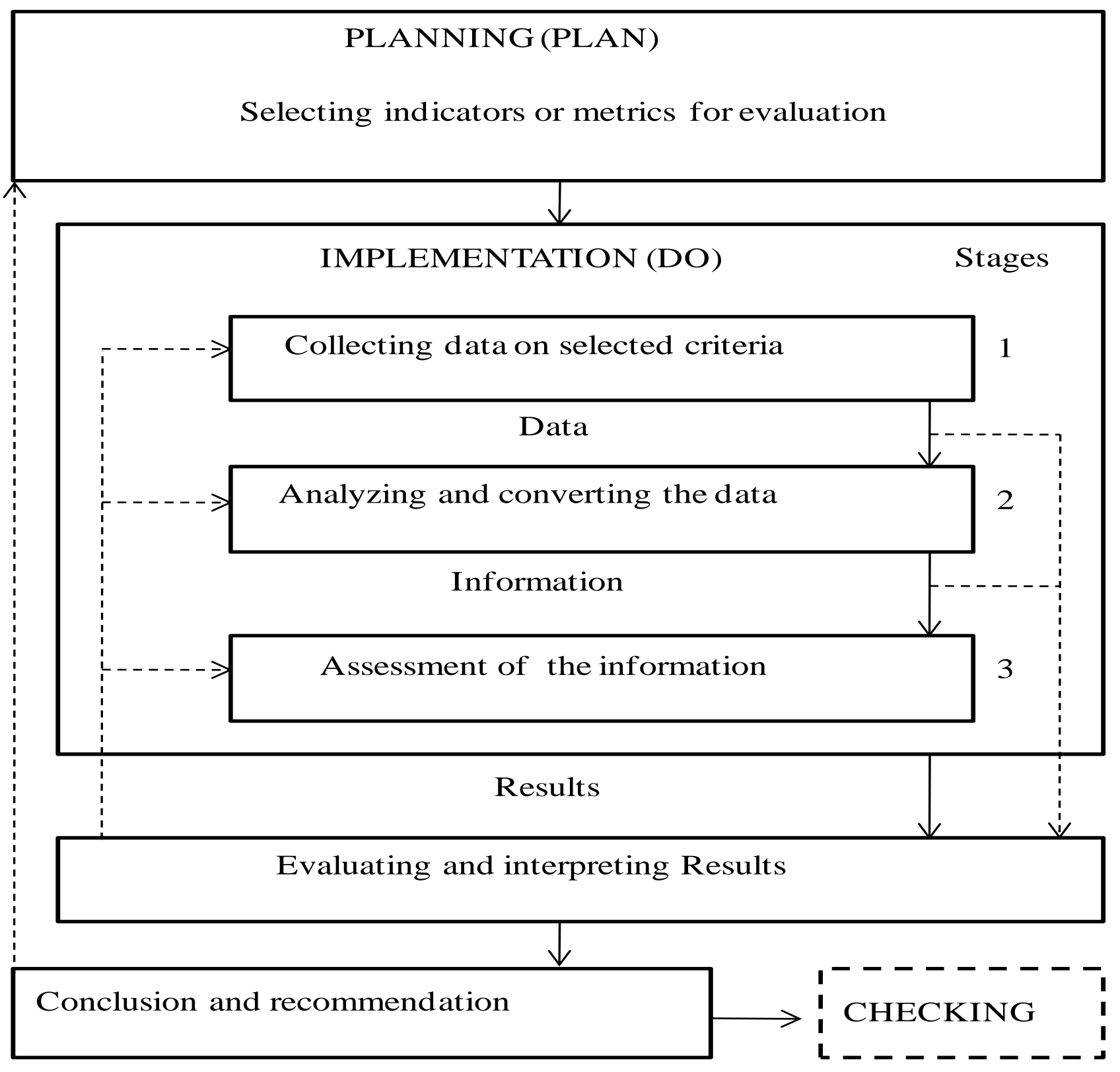

Fig. 2: Modified flow chart explaining methodology (Stone and van Berkel, 2004; Viegas, 2005)

EMS development and implementation: During the EMS development and implementation stage, identified environmental aspects were evaluated for significance and risk assessment conducted as spelt out according to ISO 14004 specifications (Poder, 2006). Competence training and awareness in four key EMS training programmes (Fig. 3) were then conducted for management representatives. The results from the training constituted the basis for the implementation at the mine. All 18 business units were then assessed through a $3^{\text {rd }}$ party certification audit for the first year, followed by a surveillance audit in the second year.

Audit, certification and data collation: During the certification audit, standard scores for implementation 
of systems procedures in the Plan-Do stages at the various business units were collated. Audit trails were scored for a maximum of 2 marks for compliance, 1 mark for partial compliance and 0 for non-compliance. The base mark for effectiveness of systems procedures was set at a score of $90 \%$. Data from the certification audit of the implementation by business units from both company and key supply chains were sourced based on availability (Carlson, 2002). Progress of valued performance criteria such as environmental observations from audits, environmental training programs, environmental aspects identification and significance rating for the two (2) years were assessed from established audit reports. Results collation was done according to the modified Plan-Do model outline in Fig. 2.

\section{RESULTS AND DISCUSSION}

During the initial audit, nine out of the ten systems procedures covering planning, and implementation and operation, scored $90 \%$ or more. All three procedures under planning were above 95\%. Out of the seven systems procedures under implementation and operation, six of them scored below 95\%, while Emergency preparedness and response procedure (EPR) scored as low as $83.1 \%$ (Fig. 4).

Evaluation of environmental aspect and impact identification during the initial audit and the follow-up audit indicated an increase by an overall average of $151 \%$ (Fig. 5). Similarly, competence training and awareness also increased by an overall average of $104 \%$ (Fig. 3). There was however an overall decrease in significance rating by an average of $12 \%$ (Fig. 6). The number of audit observations made over the same period also decreased by $64 \%$ (Figs. 7 and 8). The trend in aspect classification during the second audit year appeared to be a reverse of that of the first year (Fig. 6). That is, the order: Threats (50) $>$ Very significant (32) > Significant (13) in the first audit year got reversed as Significant (52) > Very significant (29) > Threat (13) during the second year.

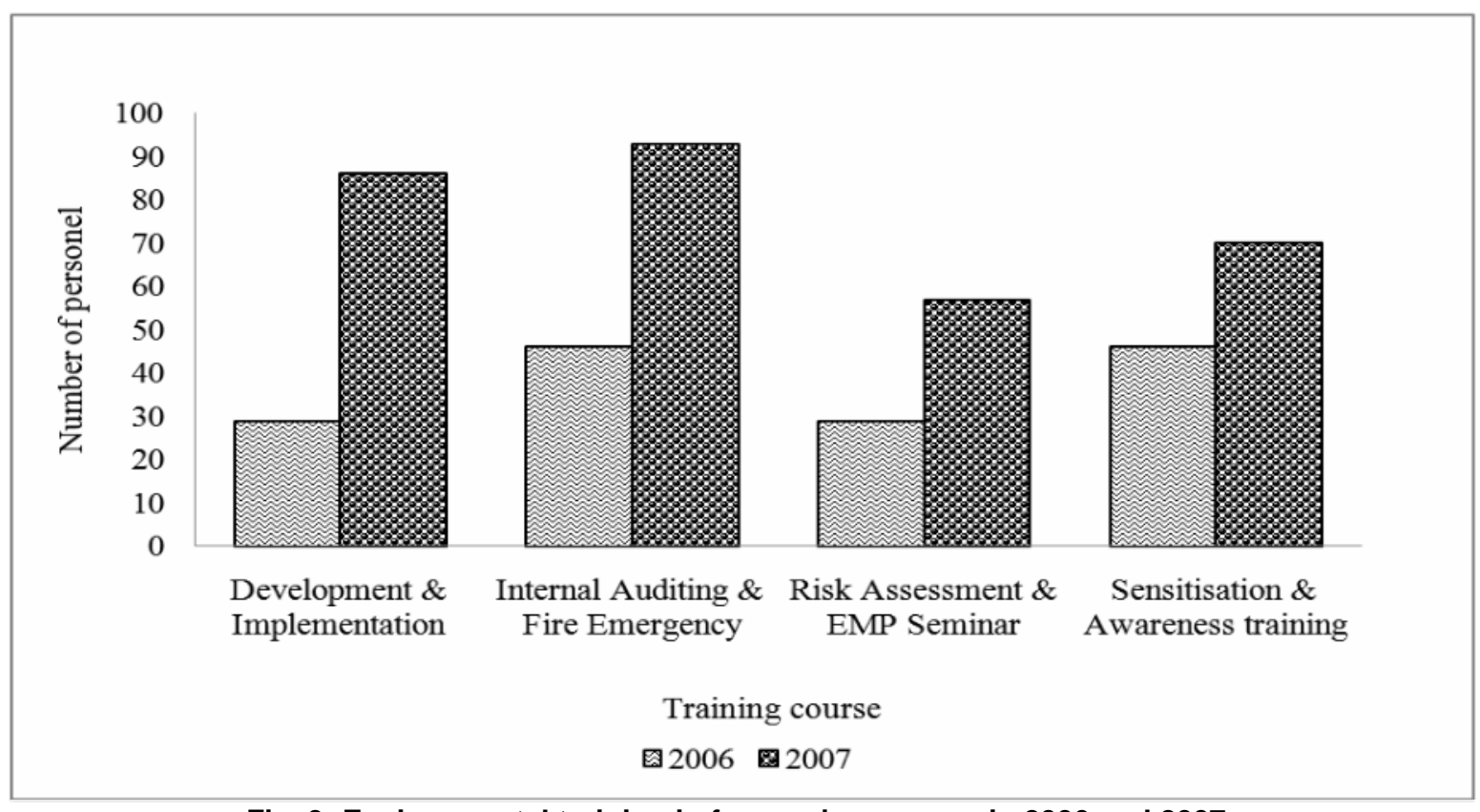

Fig. 3: Environmental training in four major courses in 2006 and 2007. 


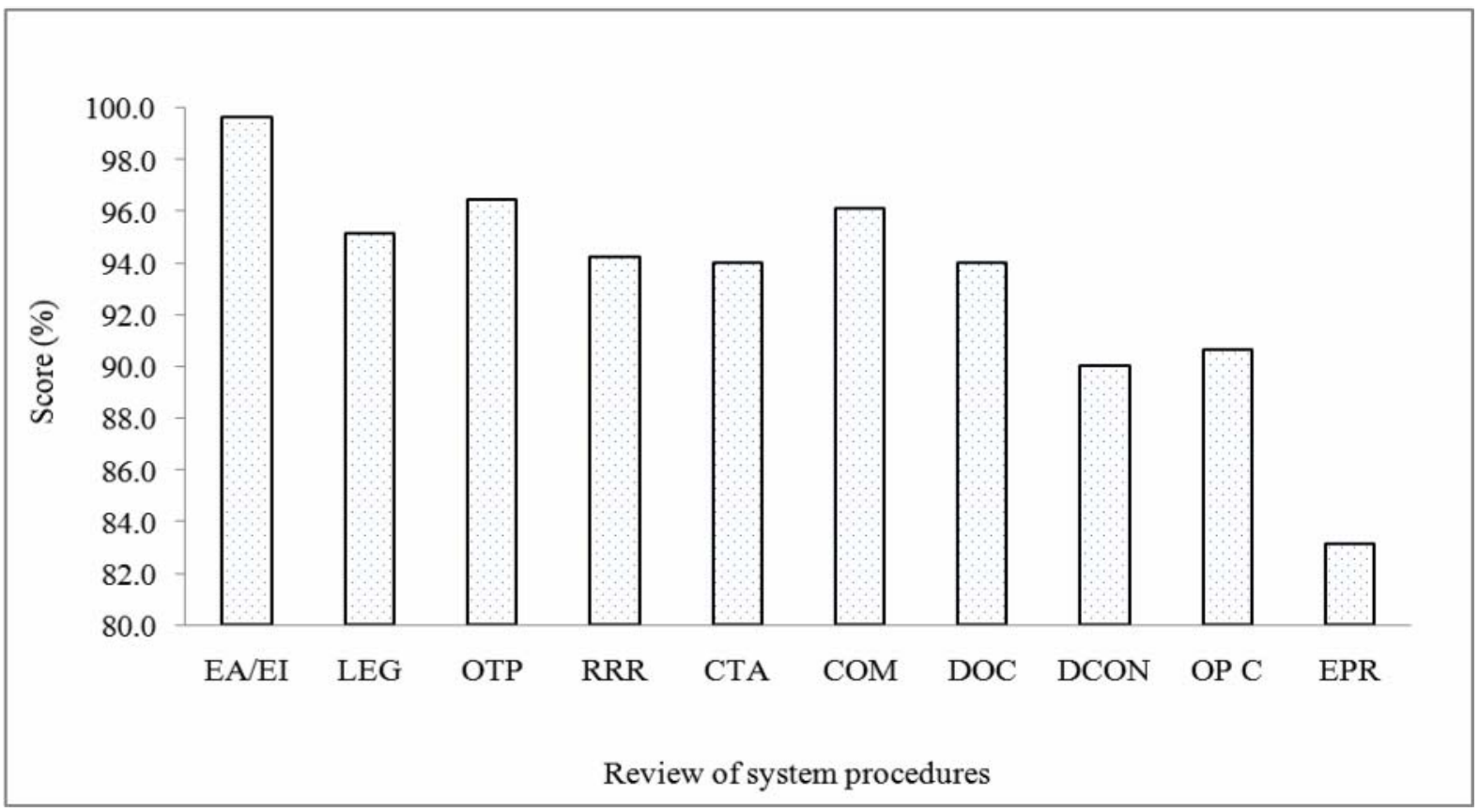

Fig. 4: Effectiveness of the review of systems procedures at the time of certification.

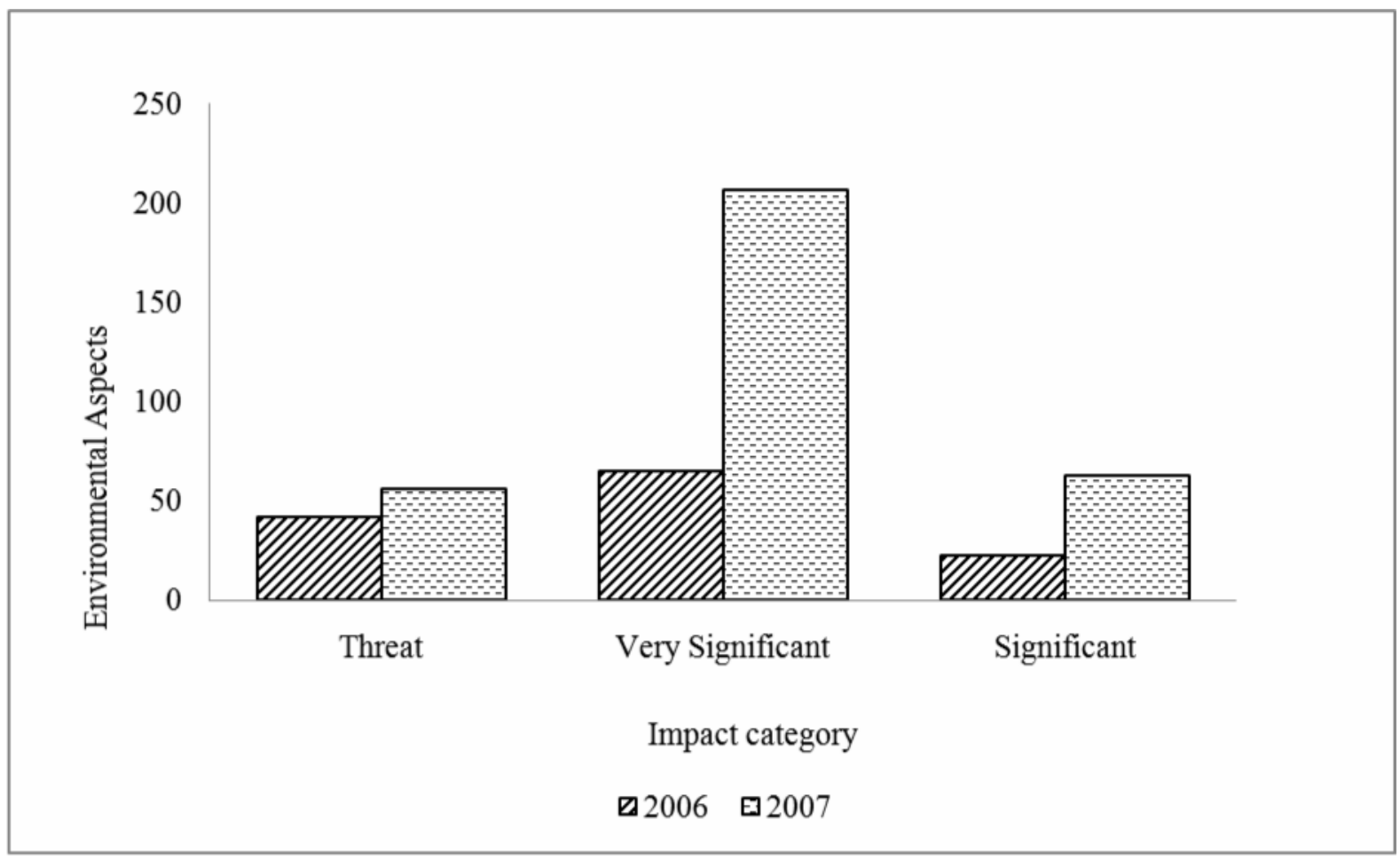

Fig. 5: Environmental aspect identification per category in 2006 and 2007. 


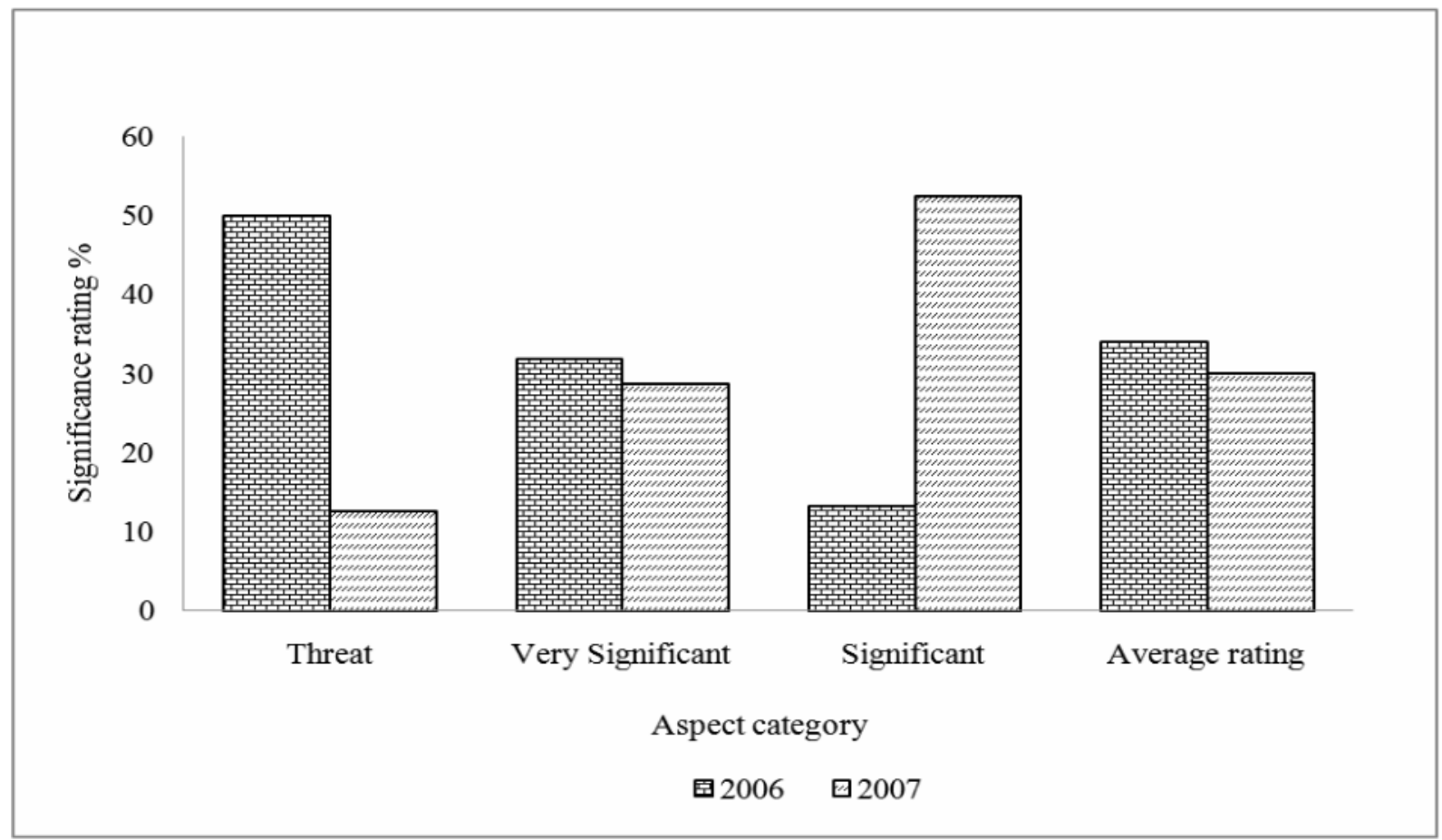

Fig. 6: Significance rating per aspect categories in 2006 and 2007.

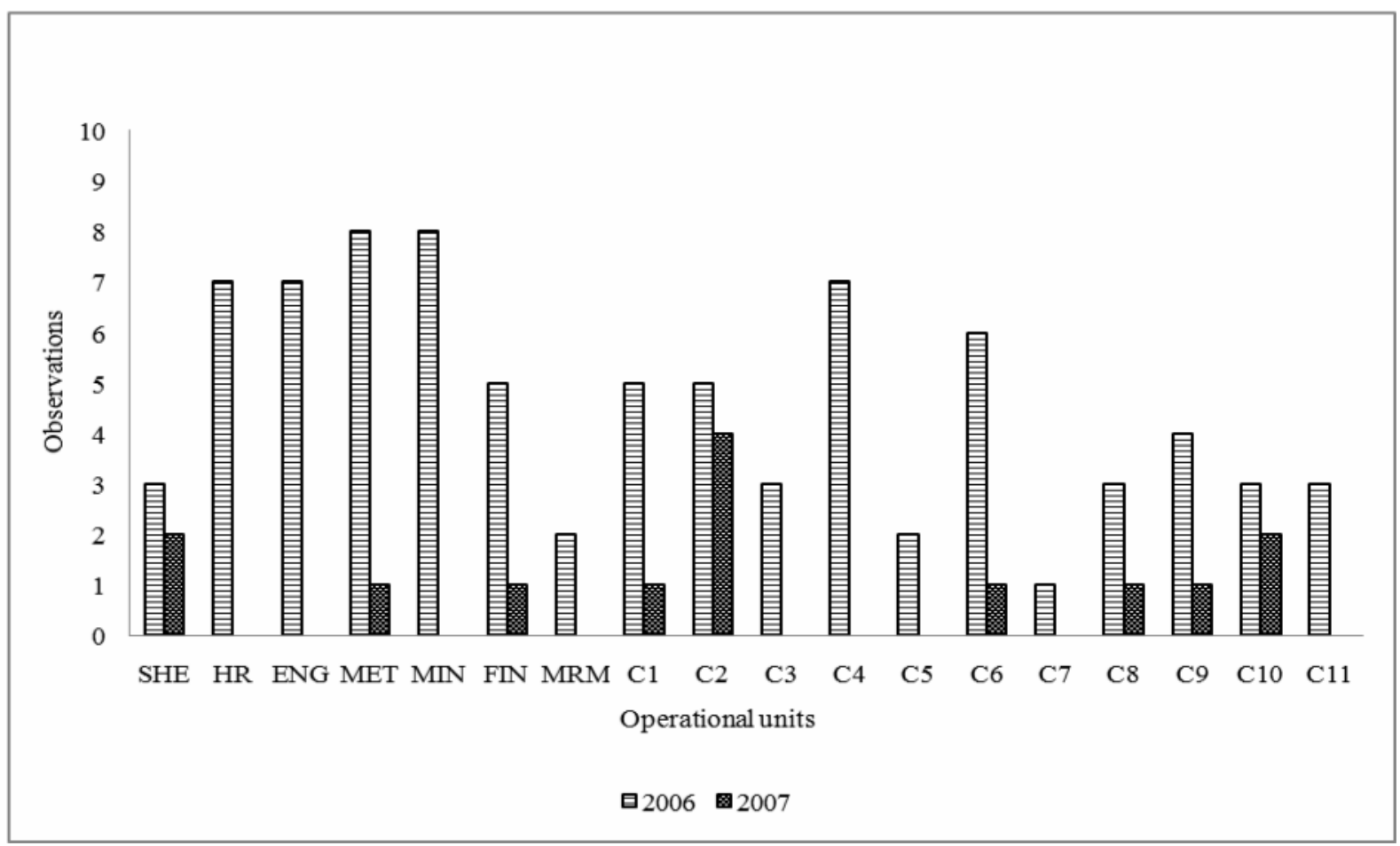

Fig. 7: Audit observations among operational units in 2006 and 2007. 


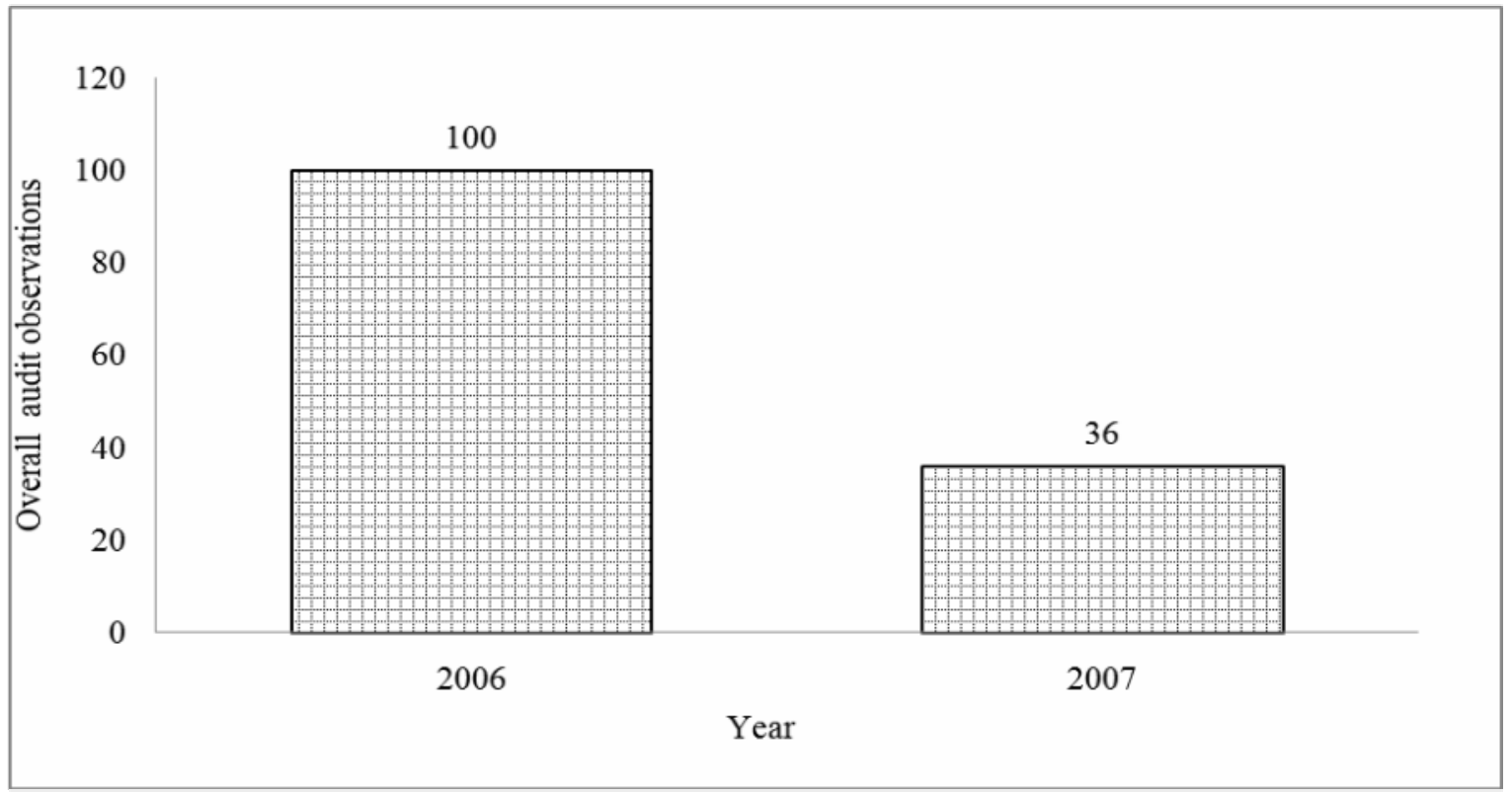

Fig. 8: Overall audit observations in 2006 and 2007.

In Fig. 9, five (5) out of eleven (11) observations $(45 \%)$ of the supply chain business units had increased percentage changes in audit observations, while two (2) out of seven (7), constituting about $29 \%$ had percentage increase at the company's business units. Twelve (12) out of eighteen (18), constituting about $67 \%$ of the business units performed weakly (i.e. scored 94\% and below) (Fig. 10).
Similar trend was observed in Fig. 11, with supply chain business units marginally upstaging company business units in performance in emergency preparedness and response. Correlation of the effectiveness of implementation of systems performance and emergency preparedness and response is 0.59

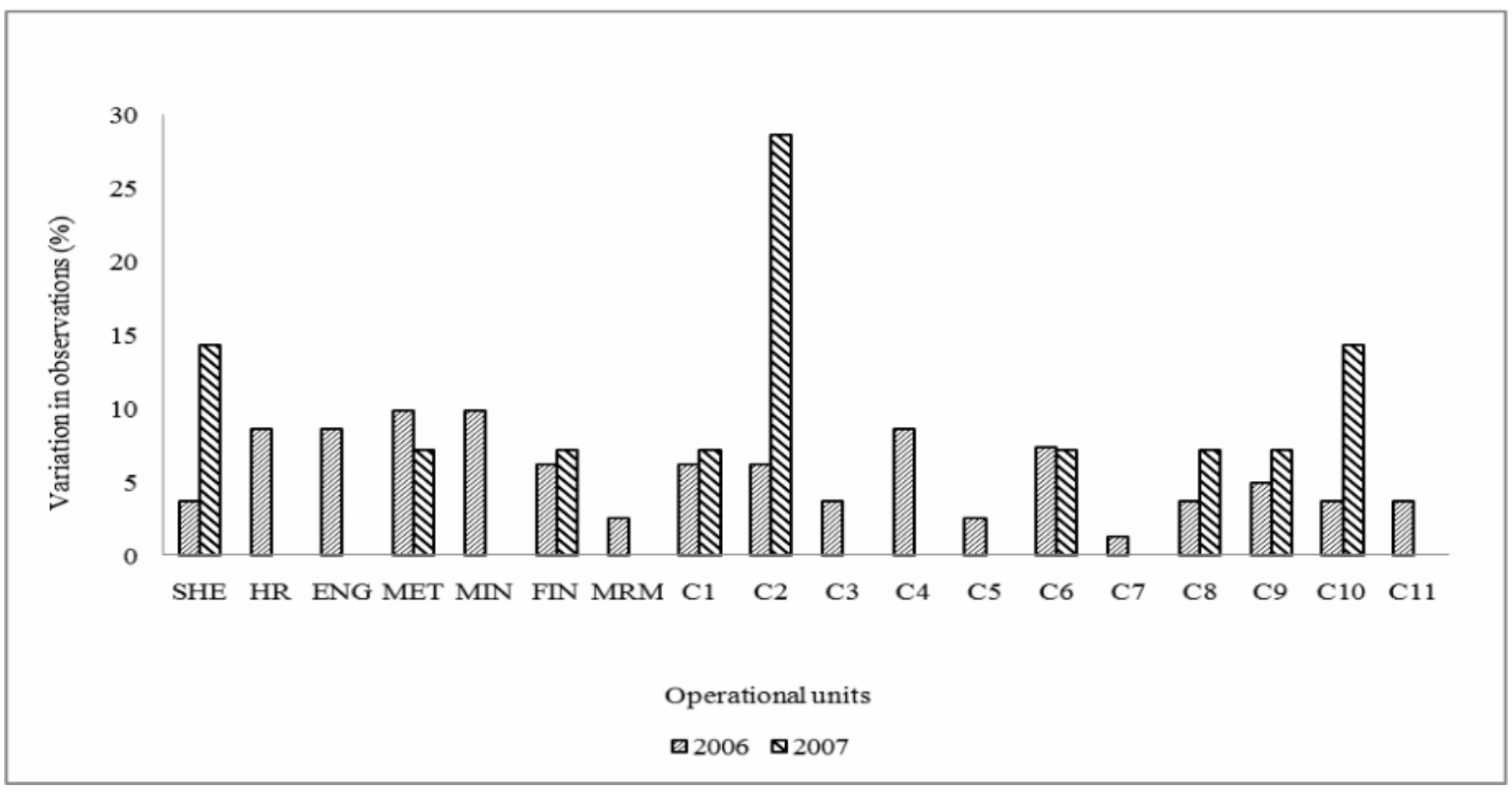

Fig. 9: Percentage variations in observations among bussiness units. 


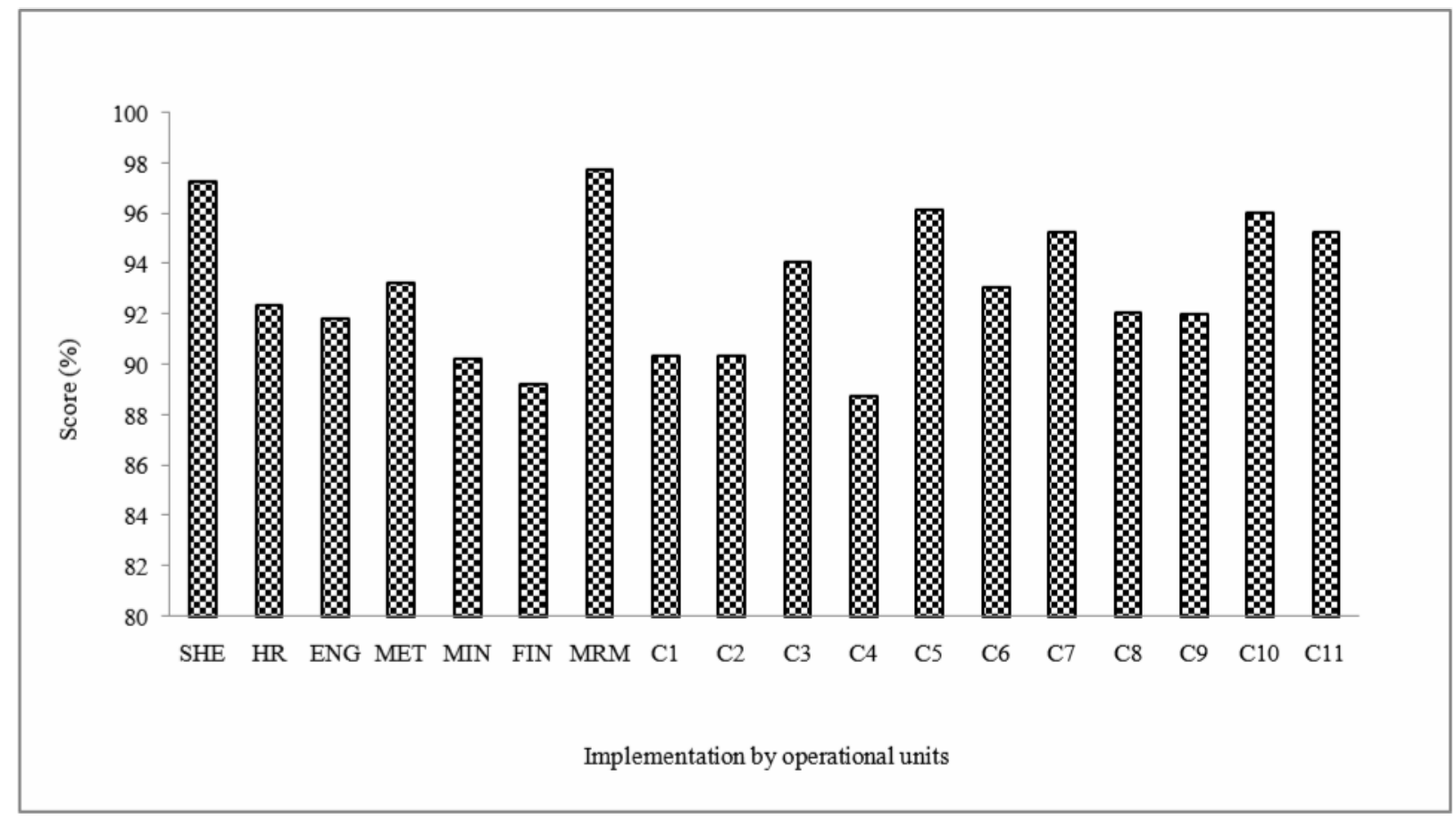

Fig. 10: Scores indicating effectiveness of systems implementation among business units.

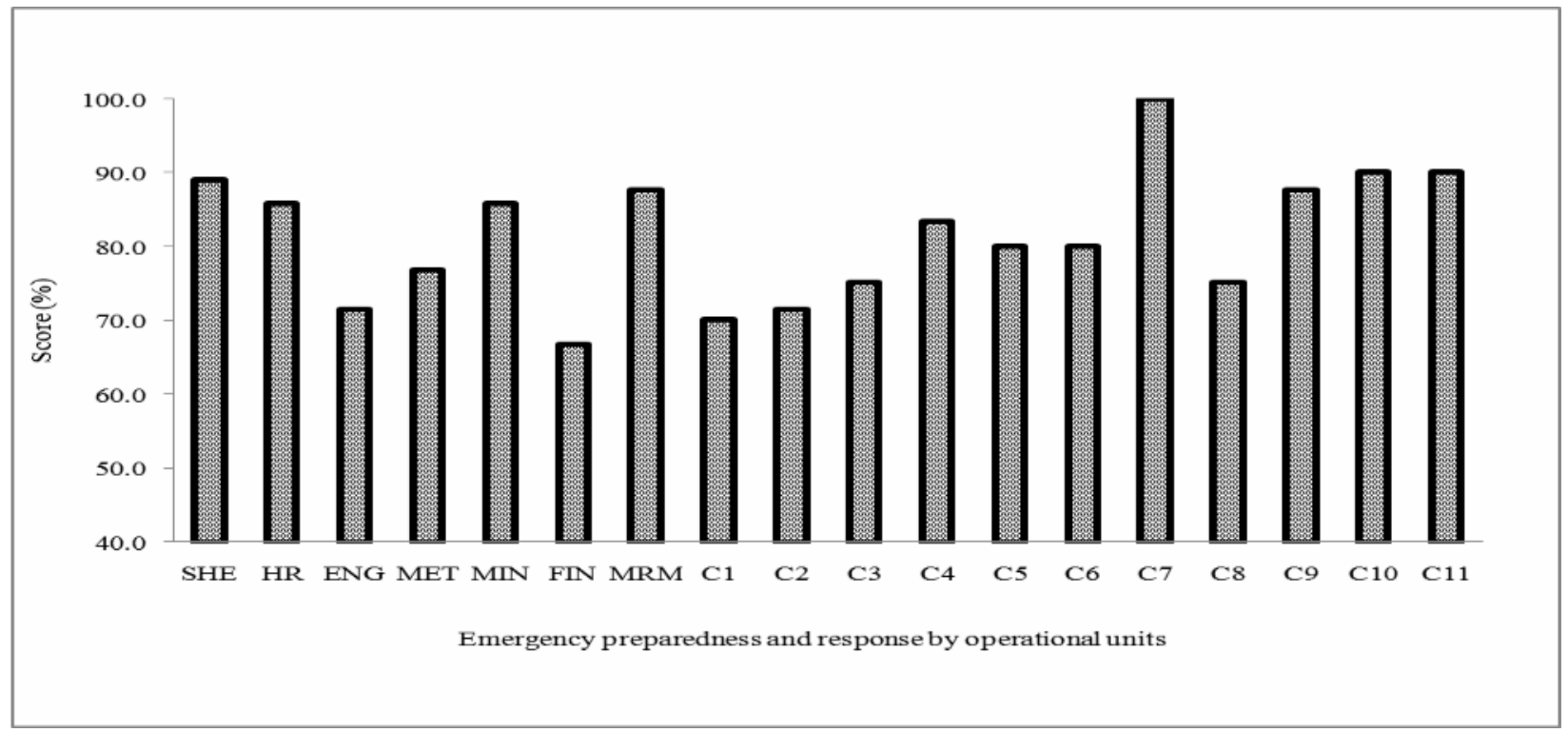

Fig. 11: Scores for the implementation of emergency preparedness and response among business units

Figures 3, 5, 6, 7 and 8 showed increased performances in environmental aspect and impact identification, training and competence and environmental aspect classification. This suggests increased awareness and zeal to participate in the process during the second year of implementation, thereby resulting in overall decrease in significance rating and environmental observations concerning the implementation of systems elements. The increased awareness and motivation for seeking the ISO 14001 certification and the perception of the EMS effectiveness among other factors served as key growth factors (Fryxell et al., 2004). The weak performance in the first year was probably due to inadequate information on the issues at hand, and also weak initial understanding of the ISO 14001 
standards concept (Hassell, 2005; Massoud et al., 2010).

During the first year, the company had to rely on external expertise at a high cost in establishing the planning stage, but in the second year, as many as were trained in the first year became instructors, thereby easing the cost of training. This implied that as the premier group became more experienced; many more have also gained enough understanding to be able to effect changes by creating further awareness. Massoud et al. (2010) indicated lack of funds and infrastructure as challenges of implementing ISO 14001 in developing countries, but this was not the case at the Obuasi mine. As part of a multinational company that has all its subsidiaries in other parts of the world already certified, the major challenge was with the understanding of the concept and the awareness in the local industry. Experience from the first year's activities indicated that it was difficult for many, including even some middle level managers to believe that a programme like ISO 14001 standards could actually improve the fortunes of a company that has already known much success in the recent past.

The high percentage scores for the planning stage, particularly Environmental Aspect and Impact contradicts previous observations that such stages are always difficult (Mohammed, 2000; Babakri et al., 2003; Zobel and Burman, 2004; Poder, 2006). It is therefore apparent that challenges to the success of an EMS in industry such as mining may not only be due to the difficulty in understanding the company's aspects and impacts, but rather, the necessary inputs in order to make it possible for the stage to be understood. For example, in the local industry, there was enough injection of foreign expertise at the planning stage at a high cost, which made it possible for the in-depth initial understanding of the company's aspects, as indicated by Massoud et al. (2010). The high performance in environmental aspects identification and in significance rating of the aspects were due to good risk assessment of the issues (Poder, 2006), which helped to define the aspects and impacts succinctly by the joint team of both local implementing group and the hired foreign experts. The percentage variation in environmental observations during the audits over the two years indicates a progressive response among the business units as a result of better understanding and increased awareness of the ISO 14001 standards concept with time.
Initial weaknesses in audit observations within the first audit year were partly due to apathetic attitudes at the implementation stage (Stone and van Berkel, 2004). For example, a procedure like emergency preparedness and response could attract exorbitant levels of funds, as well as dissipate so much manhour during mock emergency drills, and these often serve as a demotivation to management and supervisors. The Lexington Group (1999) observed that a newly introduced management system often encounters such passive resistance from many employees unless there is an effective awareness training program.

Other sources of weakness during the establishment and implementation included the lack of guide tools which are normally not as popular as the standards being established, the lack of specific conceptualized methodologies to express analytical data on such subjects, and weak initial understanding of the ISO 14001 standards concept. These weaknesses have invariably been attributed to inadequate evaluation processes and lack of adequate expertise at the local level, especially during the initial stages of implementation, among others (Hassell, 2005; Massoud et al., 2010). Viegas (2005) observed that, out of as many as 2,940,000 ISO 14001 Standards, only 27,100 of ISO 14031 (109:1) existed, implying that under the circumstances, guide tools were not applied together with EMS based on ISO 14001 standards.

Misplaced responsibility and authority may also result in weaknesses. For example, in the local industry, the idea to split Safety, health and environment into various units affected the implementation of EPR among company business units, where EPR issues are more or less handled directly by the Safety section. Subsequently, execution of the procedure could not permeate the entire fabric of the scope for implementation. This observation reflected in better performances of supply chains in implementing EPR, since among the supply chains, SHE issues are coordinated by one unit and thereby making it much easier to address EPR issue more accurately.

Group certification concept also affected the quality of the implementation, as manifested in the generally poor response of supply chains to environmental observations compared with company business units. Coelho et al. (2000) observed that, most management systems, particularly those based on the ISO standards consider individual companies 
only, and do not address the supply chains as an integral part of the company. The group certification resulted in over simplification of the system, which may have introduced some errors in the management of the system (Hassell, 2005). According to Hassel (2005) supply chains often form affiliations with company business units, instead of focusing on their own internal structures and this result in oversimplification. That notwithstanding, group certification on the other hand ensures that overlapping duties are accounted for, in multiple parallel schemes that probably reduced cost of implementation (Hassell, 2005). Therefore, a perfect balance between the above opposing factors is required for maximum output of implementation in relation to group certification.

The long period of operation, with its attendant legacy issues (AngloGold Ashanti Report to Soceity, 2007) and complexity of company operations made it difficult for the company of study to fully achieve maximum effectiveness during the implementation. This is so because of the absence of a necessary guide tool such as ISO 14031 from the onset of project implementation, which could have served as a didactic tool (Viegas, 2005). Consequently, a long period of observation is required to explore tangible effects of the system on the environmental performance after adoption of the standard by the organization.

Finally, weaknesses in standards being implemented might become a disincentive for effective environmental management as project managers may take advantage of the apparent liberal terms of some of the standards, which seem to offer suggestions rather than provide enforcement (ISO 14001:2004; 2008).

\section{CONCLUSIONS AND RECOMMENDATIONS:}

Both technical and managerial issues determined the quality of the ISO 14001 Standards implementation. However, the process could be improved through increased training. The study has also shown that the EMS based on ISO 14001 has immense potential for good environmental practices and that ample time is needed to explore tangible effects of the system on environmental performance, in view of the huge legacy issues at hand. Both positive and negative issues alike have created the platform for the redress of candid environmental issues, and also established assurance to regulating bodies that, nagging issues will be controlled in a matter of time. It has also been highlighted that challenges of the success of the ISO1 4001 Standard programme depends largely on issues of implementation. It is the view of the authors that:

- Performance reward systems could be established for meeting the environmental objectives and targets established in the management system through annual performance appraisals of personal performance in terms of contributions to the success of the management system, objectives and targets.

- A guide tool is necessary right from the start of the implementation of ISO 14001 standards. By that, Aspects and Impacts identification and classifications, which constitutes the bedrock of good management systems, can be correctly established from the very on-set.

- A perfect integration of supply chains with the company's business units must be established and developed in order to ensure a successful systems implementation. High level of synergism between both implementing groups will draw the balance between the danger of the system over simplification and the needed cut down on cost.

- Finally, top management commitment must not be compromised whatsoever because of the daunting challenges that are associated with the venture.

\section{ACKNOWLEDGEMENTS:}

Much indebtedness goes to the Management of Obuasi mine, Ghana, especially their Environmental Department for the assistance given during the final collation of this data. The initial data for this script was gathered when the first author was the ISO 14001 Coordinator for the mine during the implementation of the Standards at the mine.

\section{REFERENCES}

Allotey J.Y., Amoyaw-Osei, J., Appah-Sampong, E., BaduYeboah. K and Kudjawu, J(2006). Development of improved "environmentally sensitive areas" in Ghana's environmental assessment regulations (Legislative Instrument 1652, 1999) Final Report 87p

AngloGold Ashanti Report to Society (2007). Programme to deal with environmental Legacy Issues at Obuasi; Case Studies - Environment

Asante-Duah, D. K (1998). Risk assessment in environmental management. A guide for managing chemical contamination Problems. Wiley, Chichester. 
Babakri, K.A., Bennet, R and Franchetti, M (2003). Critical factors for implementing ISO 14001 standards in United States industrial companies. Journal of Cleaner Production 11:749-752

Barla, P (2007). ISO 14001 certification and environmental performance in Quebec's pulp and paper industry. $J$. Environ. Econ. Manage.53, 291-306.

Carlson, R (2002). Environmental Performance Indicators, Published in July, $22^{\text {nd }}$ Issue of INSIGHT

Coelho, J.F.G.M., Moy, D and Edwards, R (2000). Performance evaluation Management Systems for organizations and supply chains based on the AS/NZS ISO 14031:2000; (derived in part from PhD studies of José Flávio Coelho)

Coelho, J.F.G.M and Moy, D (2001). Integrated management systems and Performance Evaluation - a case study in Brazil', paper presented to Improving business: Proceedings of the Annual Quality Conference, 25-27 November 2001, Australian Organization for Quality, Brisbane

da Rosa D and Lyon, J.S (1997). Golden Dreams, Poisoned Streams, Part 1 \&2; Mineral Policy Centre, Washington D.C, pp.64-68

Emilsson, S and Hjelm, O (2002). Implementation of standardized environmental management systems in Swedish local authorities: reasons, expectations and some outcomes. Environ. Sci. Policy. 5, 443-448

Fletcher, W.J (2005). The application of qualitative risk assessment methodology to prioritize issues for fisheries management - ICES Journal of Marine Science, 62:1576 1587

Fryxell, G.E., Lo, C.W and Chung, S.S (2004). Influence of Motivations for Seeking ISO 14001 Certification on Perceptions of EMS Effectiveness in China. Environmental Management Vol. 33, No 2, pp.239-251

Hassell, J (2005). A Review of Existing Certification Impact Evaluation Methodologies; A Report of the ISEAL Alliance R049 Internal Report; p5-17

ISO 14004 (1996). Environmental management systems. General guidelines on principles, systems and supporting techniques.

ISO 14001:2004 (2008). Environmental Management systems requirements for guidance:International Standards for Business, Government and Society.

Massoud, M.A., Fayad, R., Kamleh, R and El-Fadel, M (2010). Environmental Management System (ISO 14001) Certification in Developing Countries: Challenges and Implementation Strategies. Environ. Sci. Technol., 44, 1884-1887
Matouq, M (2000). The ISO 14001 EMS implementation process and its implications: A case study of central Japan. Environmental Management, 25 (2), 177-188

Mohammed, M (2000). The ISO 14001 EMS Implementation Process and Its Implications: A Case Study of Central Japan. Environmental Management Vol. 25, No, 2 pp.177188

Morhardt, J.E., Baird, S and Freeman, K (2002). Scoring corporate environmental and Sustainability Reports using GRI 2000, ISO 14031 and other criteria; RobertsEnvironmental Center, Claremont McKenna College, USA; John Wiley \& Sons, Ltd and ERP Environment.p216, 220

Nouri, J., and Toutounchian, S (2004). Application of environmental management system-ISO 14001:1996 in urban environments and municipalities. International Journal of Environmental Science and technology Vol 1, No 2, pp 109-117

Petroni, A (2001). Developing a methodology for analysis of benefits and shortcomings of ISO 14001 registration: lessons from experience of a large machinery manufacturer. J. Clean. Prod. 9, 351-364.

Poder, T (2006). Evaluation of Environmental Aspects Significance in ISO 14001: Springer Science + Business Media Inc. Environmental Management Vol. 37, No.5, pp.732-743

Seifert, E.K (2005). EPE According to ISO 14031: Concept, Experience, and Revision Issues, Wuppertal Institute, Germany, Idea Group Inc. Idea Group Inc.

Seppala, J. (1994). The environmental risk analysis in the industry. Waters and the Environment No 571. National Board of Waters and the Environment, Helsinki, Finland

Singh, G (1987). Water quality deterioration due to acid mine drainage. International Journal of Mine Water, Vol 6 No 1 pp 49-61

Stone, L and van Berkel, R (2004). Environmental Performance Measurement: A Stepping-stone towards sustainability management Waste \& Recycle 2004 Conference, pp. 269-279

The Lexington Group (1999). Best Practices Guide: Application of ISO 14000 Environmental Management Systems (EMS) for Municipalities.p.2, 38-39.

Viegas, M (2005). Environmental performance evaluation; ISO 14031:1999 and the Future ISO 14031 - ISO TC 207 Plenary Slide No 2

Zobel, T and Burman, J.O (2004). Factors of importance in identification and assessment of Environmental aspects in an EMS context: experiences in Swedish organizations. Journal of Cleaner Production 12:13-27. 